\title{
Effect of Backward Treadmill Training on Genurecurvatum in Cerebral Palsied Children
}

\author{
RAMY A. KHIDR, M.Sc.*; HEBATALLAH M. KAMAL, Ph.D.**; AMIRA E. EL BAGALATY, Ph.D.** and \\ HASSAN M. EL BARBARY, M.D.*** \\ Physiotherapist in Al Shohadaa Central Hospital at Al Monufia Governorate*, Egypt, Department of Physical Therapy for \\ Pediatrics, Faculty of Physical Therapy** and Department of Orthopedics, Faculty of Medicine***, Cairo University
}

\begin{abstract}
Background: Cerebral palsy (CP) is described as a group of disorders of the development of movement and posture, causing activity limitation that are attributed to non-progressive disturbances that occurred in the developing fetal or infant brain. Many patients with CP walk with a knee recurvatum pattern. A recurvatum gait can also be quite disabling and has been reported to cause proximal tibial deformity. Knee recurvatum has been described to occur in $8 \%$ to $40 \%$ of patients with $\mathrm{CP}$.
\end{abstract}

Aim of Study: To determine effect of backward treadmill training on genurecurvatum in cerebral palsied children.

Subjects: Thirty ambulant cerebral palsied children were selected by simple random way for this study from outpatient clinic of Al Shohadaa Central Hospital. Their ages ranged from 4-8 years. Their knee hyperextension ranged from 10 to 20 degrees in X-ray. No other knee deformities, surgical intervention or fractures. They were assigned randomly into two groups equal in number, each group consisted of 15 children; Group A: They received backward treadmill gait training exercise for thirty minutes for three times per week over three successive months with a specifically designed physical therapy program for one hour for each child, three times weekly, over three months. Group B: They received only the same designed physical therapy program given to group A.

Material and Methods: All children's baseline data (radiological evaluation) were collected before and after treatments.

Results: There was a statistically high significant decrease in the mean value of knee joint angle of both groups (A and B) where ( $p$-value <0.0001) measured by $\mathrm{X}$ ray and this high significant reduction is in favor of group (A).

Conclusion: This article shows that backward treadmill training with a specifically designed physical therapy program considered to be a safe, easy to use and very effective physical therapy program on genurecurvatum in cerebral palsied children.

Correspondence to: Dr. Ramy A. Khidr, Physiotherapist in Al Shohadaa Central Hospital at Al Monufia Governorate, Egypt
Key Words: Treadmill-Backward walking - Genurecurvatum - Cerebral palsy.

\section{Introduction}

CEREBRAL palsy is described as a group of disorders of the development of movement and posture, causing activity limitation that are attributed to non-progressive disturbances that occurred in the developing fetal or infant brain. The motor disorders of cerebral palsy are often accompanied by disturbances of sensation, cognition, communication, perception and/or behavior [1] .

Children with cerebral palsy are functionally limited to varying degrees because of their decreased central control and coordination of their movements. The effects of growth predispose children with neurological impairments to the secondary problems of muscle contractures, bony deformities, and unusual gait abnormalities. Health care programs aim to prevent deformities and encourage the development of functional and independent skills and abilities [2].

Genurecurvatum is a deformity in the knee joint, so that the knee bends backwards. In this deformity, excessive extension occurs in the tibiofemoral joint. Genurecurvatum is also called knee hyperextension and back knee. Hyperextension of the knee may be mild, moderate or severe. The normal range of motion (ROM) of the knee joint is from 0 to 155 degrees in children. Full knee extension should be no more than 10 degrees. In genurecurvatum (back knee), normal extension is increased [3].

Patients with cerebral palsy (CP) walk with several described gait patterns. Many patients with $\mathrm{CP}$ walk with a knee recurvatum pattern. Knee 
recurvatum during gait is described as knee hyperextension in stance phase. A recurvatum gait can also be quite disabling and has been reported to cause proximal tibial deformity. Knee recurvatum has been described to occur in $8 \%$ to $40 \%$ of patients with $\mathrm{CP}$ and is associated with hamstring lengthening in some cases. The recurvatum starts in stance phase once the tibial movement stops, and the femur continues forward progression [4].

Efficiency of walking and the development of independent gait are often the focus of therapeutic interventions for children with CP. Motor learning theory suggests that when encountering a new motor skill or adapting a motor skill to a specific situation, a group of interconnected neurons is selected from a primary neuronal repertoire based on prior experience of the task. Generated movement patterns and postural adjustments are then refined via afferent feedback. Therefore, it has been argued that to develop and improve a motor skill such as walking, opportunities for repetitive practice of the skill need to be offered. For this reason use of a mechanical treadmill may improve walking in children with CP. Treadmill walking provides increased opportunity to repetitively train the whole gait cycle, facilitate an improved gait pattern. Improved walking has the potential to increase the mobility and positively influence the societal participation of children with $\mathrm{CP}$ at home, at school and in the wider community [5].

Genurecurvatum is so common in children with cerebral palsy so its treatment is highly recommended. The development of efficient and independent walking is an important therapeutic goal for many children with cerebral palsy (CP). Consequently, there has been growing interest in determining the effects of treadmill training programs for these children. Treadmill training is safe and feasible for children with $\mathrm{CP}$ across a wide range of ages and functional abilities. Children with more severely affected walking ability significantly increased their walking speed and gross motor performance after training [6] .

Walking backwards gives a chance to work out all of those muscles in legs, such as quadriceps and calves, which take a backseat to hamstrings and glutes during regular walking. It also works out hamstrings in a different way, and walking backwards for just 10-15 minutes, four days a week for four weeks has been shown to increase strength in hamstrings [7].

The purpose of this study was to investigate the effect of backward gait training on treadmill on Genurecurvatum in cerebral palsied children.

\section{Patients and Methods}

This study was conducted at the Outpatient Clinic of Al Shohadaa Central Hospital, El Minoufia through the period from January 2017 to July 2018.

\section{Patients:}

Thirty ambulant cerebral palsied children were selected by simple random way for this study. Their ages were ranged from 4-8 years. Their knee hyperextension ranged from 10 to 20 degrees in $\mathrm{X}$ ray image. No other knee deformities, surgical intervention or fractures. They were assigned randomly into two groups equal in number, each group consisted of 15 children; Group A: Received backward treadmill gait training exercise for thirty minutes for three times per week over three successive months with a specifically designed physical therapy program for one hour for each child, three times weekly, over three months. Group B: received only the same designed physical therapy program.

\section{Mathods:}

All children in both groups (A and B) had been evaluated at base line before treatment and after 3 successive months of treatment by using:

Radiological evaluation: For measurement of the angle between axis of femur and axis of tibia by X-Ray for all children in sagittal plane from standing position.

\section{Procedure:}

Calibration of devices which used in the study was done before each child evaluation.

\section{A- Evaluation procedures:}

\section{Radiological evaluation:}

Normally the angle between axis of femur and axis of tibia should be 180 degree and in case of genurecurvatum it exceeds to be 10 or more.

- Measuring angle between long axis of femur and tibia by X-rays before and after 3 successive months of treatment.

- The child stood in front of X-ray device by his side.

All angles assessed pre study were between 10 to 20 degrees of knee hyperextension.

B- Treatment procedure: Children were assigned into two groups:

- Group A (study group): Received backward treadmill gait training exercise with a specifically designed physical therapy program. 
- Group B (control group): Received only the same designed physical therapy program.

For Group A (study group): Treadmill training.

Treadmill training program was applied for study group only (A) thirty minutes for three times per week over three months in conjunction with the specifically designed physical therapy program

\section{Description of treadmill training:}

A- The child was standing on treadmill by his her back to make backward walking before starting the treadmill device.

B- Child should stood without tilting or leaning to any side.

C- For safety the child grasped the hand rails properly and was observed.

D- Starting the device and child was steady.

E- Adjusting the program speed to be suitable for age and speed to become 1-3 kilometer per hour [8].

F- Child was instructed to walk backward with foot clearance from treadmill ground.

G- No inclination in treadmill level.

H- The child walked 30 minutes with 2 interval break for 5 min every 10 minutes.

\section{For group $A \& B$ :}

Specifically designed physical therapy program based on neurodevelopmental technique will be applied one hour for each child, three times weekly, over three months period and include the following exercises:

A- Facilitation of righting \& equilibrium reactions: By using swiss ball [9].

B- Strengthening exercises: To back extensors and abdominal muscles to improve back mobility and strength [10].

C- Graduated active exercises: To knee flexors muscles to enhance erect body posture and knee stability [11].

D- Joint Compressions: To help to promote increased co-activation of muscles around the joint and help child maintain joint in alignment against gravity [12] .

E- Muscle stretching: Will be used to maintain the length and elastic recoil of all muscles liable to be tight specially the Achilles tendon in the lower limbs [13].

F- Positioning: Of the spastic muscles of the upper and lower limbs in the opposite direction of its spasticity as reflex inhibiting patterns [14].

\section{Statistical procedures:}

\section{Data analysis:}

Data were collected as follow: Before starting (pretreatment) \& after three months (post treatment). Statistical analysis was used for data collection to calculate mean, standard deviation and percentage of change. Differential statistical analysis was used in the form of paired $t$-test to compare pre and post treatment mean values in the same group. Independent $t$-test was used to compare between groups pre and post treatment. Level of significance was determined at $p$-value $<0.05 . p$ value $<0.05$ indicates significant results and $p$ value $<0.001$ indicates highly significant results.

\section{Results}

Table (1) represents mean values and standard deviation of physical characteristics including age and sex of all children in both groups (A and B) and revealed the following: The age of children in group (A) ranged from 5 to 8 years old with mean value of (5.53 \pm 0.91$)$, The age of children in group (B) ranged from 4 to 8 years old with mean value of (5.53 \pm 1.06$)$, Sex distribution of all children in group (A) and revealed the following: Male children in group (A) are 6 of 15 with percent of $40 \%$ and female children are 9 of 15 with percent of $60 \%$, sex of all children in group (B) and revealed the following: Male of children in group (B) is 9 of 15 with percent of $60 \%$ and female of children is 6 of 15 with percent of $40 \%$.

Table (1): Demographic Baseline characteristics among groups (A and B) for Physical characteristics of the Children.

\begin{tabular}{|c|c|c|c|c|c|c|c|}
\hline \multirow{2}{*}{$\begin{array}{l}\text { Physical } \\
\text { characteristics }\end{array}$} & \multicolumn{2}{|c|}{ Group A } & \multicolumn{2}{|c|}{ Group B } & \multicolumn{2}{|c|}{ Unpaird $t$-test } & \multirow{2}{*}{ S } \\
\hline & Mean & SD & Mean & SD & $\begin{array}{c}t- \\
\text { value }\end{array}$ & $\begin{array}{c}p- \\
\text { value }\end{array}$ & \\
\hline Age (years) & 5.53 & 0.91 & 5.53 & 1.08 & 0.06 & 0.93 & NS \\
\hline Sex & $\begin{array}{l}40 \% \\
\text { Male }\end{array}$ & $\begin{array}{l}60 \% \\
\text { Female }\end{array}$ & $\begin{array}{l}60 \% \\
\text { Male }\end{array}$ & $\begin{array}{l}40 \% \\
\text { Female }\end{array}$ & & & \\
\hline
\end{tabular}

SD: Standard deviation. NS: Non significant.

Comparing pre-treatment mean values between groups revealed no significant difference in all measured variables. High significant statistical difference was observed in knee joint angle when comparing pre- and post-treatment mean values of group (A), after application of Treadmill and a specifically physical therapy program. Significant statistical differences were observed in knee joint angle when comparing pre- and post-treatment mean values of group (B), after application of the same physical therapy program only. Comparing 
post-treatment mean values between both groups revealed a significant difference in knee joint angle in favor of Group (A) as shown in Table (2).

Table (2): Comparing the mean values of the angle between axis of femur and axis of tibia measured by X-ray for in both groups.

\begin{tabular}{llll}
\hline Item & Group & \multicolumn{1}{c}{ Pre } & \multicolumn{1}{c}{ Post } \\
\hline Knee angle by X-ray & Group (A) & $12.07 \pm 2.18$ & $6.33 \pm 1.58$ \\
& Group (B) & $11.08 \pm 2.3$ & $9.33 \pm 2.05$ \\
$p$-value & & 0.79 & 0.0001 \\
\hline
\end{tabular}

\section{Discussion}

Cerebral palsy is the commonly used name for a group of conditions characterized by motor dysfunction due to non-progressive brain damage early in life. There are usually associated disabilities as well as emotional, social and family difficulties. Cerebral palsies are the most common cause of childhood disability. The range of severity may be from total dependency and immobility to adequate abilities of talking, independent self-care and walking, running and other skills, although with some clumsy actions [15].

Patients with cerebral palsy (CP) walk with several described gait patterns. Many patients with $\mathrm{CP}$ walk with a knee recurvatum pattern. Knee recurvatum during gait is described as knee hyperextension in stance phase. A recurvatum gait can also be quite disabling and has been reported to cause proximal tibial deformity. Knee recurvatum has been described to occur in $8 \%$ to $40 \%$ of patients with $\mathrm{CP}$ and is associated with hamstring lengthening in some cases. The recurvatum starts in stance phase once the tibial movement stops, and the femur continues forward progression [4].

Gait can be affected by genurecurvatum. During the loading response in gait, an individual with genurecurvatum transfers bodyweight directly from the femur to the tibia without the usual muscle energy absorption and cushioning of the flexed knee. This may lead to pain in the medial tibiofemoral joint due to the compressive forces at the medial tibiofemoral compartment and is accentuated if a varus alignment is present and overload on posterolateral ligamentous structures due to the tension placed on the posterior structures and is aggravated by stepping or forceful knee extension in weight bearing. In individuals with quadriceps weakness, compensation may occur by hyperextending the knee to provide greater knee stability [16].

Significant increase in the electromyography activities of the vastus medialis obliquus, vastus lateralis and gluteus medius muscles during backward walking versus forward walking. The increased electromyography activity of knee extensors, hip abductors, and adductors may be linked to the increased cortical activation during backward walking, as there is increasing oxygenated hemoglobin concentration in the supplementary motor area, precentral gyrus, and the superior parietal lobule during backward walking versus forward walking [17].

Interestingly, walking backwards, makes heart rate tends to rise higher than it does when walking forward at the same pace, which suggests getting greater cardiovascular benefits in a shorter period of time [18]

Further, because backward walking puts far less impact on knees, this activity is ideal if there is knee pain or problems. In fact, researchers have called backward walking a safer form of training that can actually improve forward walking skills as well [19].

The results of this study are supported by Olama who found that the treadmill training with or without partial body weight can support children with $\mathrm{CP}$ to improve the gross motor function, and to enhance the lower extremity muscle strength, walking speed and endurance, as well as the Spatiotemporal parameters of the gait, and balance and quality of the life [20]

The results of the study are also supported by Grecco et al., who found that Treadmill training is more efficient, regarding functional mobility, functional performance, gross motor function and functional balance, than the training with overground walking in the children with $\mathrm{CP}$ [21].

The results of the study are consistent with Kurz et al., who revealed improvement of motor control as a result of reducing reaction time, reduction of the double support phase time of the gait and increasing the power of the lower body muscles and the performance of cardio-respiratory system. Furthermore, self-reports of the participants on effectiveness of treadmill training indicated that their motivation to continue treatment and gait independence increased, morning stiffness and the fear of falling reduced [22].

The results of the study agreed with Damiano who revealed that the use of a mechanical treadmill can improve walking in children with CP skills. Walking on a treadmill provides an opportunity for repeated training in the total gait cycle, facilitates the advanced gait model, and decreases the 
effect of poor balance on the child's ability to lift weights during walking when a body weightsupporting system is used [23]

The results of the study agreed with Masumoto, 2017, who reported that retro walking is considered an effective closed kinetic chain exercise to improve lower muscles strength and the equilibrium of the human body. Backward walking causes reduced eccentric activity of the quadriceps, while concentric and the isometric quadriceps activity was preserved [24].

The result of the study are supported by Peggy, 2016, who revealed that backward walking has many benefits like mental benefits, enhanced sense of body awareness, increased body coordination and movement in space, helps avoid workout boredom, improves overall mood, helps with sleep cycles, motivates you to step outside your comfort zone, keeps your mind guessing, sharpens your thinking skills and enhances cognitive control, increases strength in lesser-used leg muscles, improves walking technique and form, helps with balance, strengthens bones and muscles. Walking backward can help you improve your leg endurance and aerobic capacity more rapidly. That's because the challenge you are placing on your body is greater. You're forcing your body to adapt to new and unfamiliar demands, which promotes improvements and growth in your physical fitness. Your body is less familiar with walking backward, so you can expect to get more cardiovascular and benefits in a shorter amount of time. This makes your workouts more efficient and intense [8].

The results of the study are contrary to those of Dodd, 2002, who revealed that a strengthening program planned to increase muscle strength could be expected to have less effect on measurement of muscle power than on activity measurements as other factors such as sensory function, coordination, and even psychological factors contribute to motor performance [25].

The results of the study are contrary to those of Willoughby et al., who revealed that treadmill training with partial body weight support was not only more efficient for improving walking speed and walking endurance than overground walking, but also the control group got more increase in the gait endurance than the experimental group [26].

\section{Conclusion:}

The backward treadmill training have a highly significant effect on Genurecurvatum and considered to be a safe, easy to use and very effective physical therapy program on genurecurvatum in cerebral palsy children.

Further future investigations are required on larger sample, for a longer period, using different age groups as well as using different assessment tools.

\section{References}

1- HAFSTRÖM M., KÄLLÉN K., SERENIUS F., MARSÁL K., REHN E., DRAKE H. and STRÖMBERG B.: Cerebral palsy in extremely preterm infants. Pediatrics, 141 (1): 201-714, 2018.

2- EL-MENIAWY G.: Influence of ankle Kinesio Taping on ankle excursion and selected gait parameters in children with hemiparesis. Bulletin of Faculty of Physical Therapy, 15 (2): 367-426, 2010.

3- BENSON M., FIXSEN J. and MACNICOL M.: Children's Orthopedics and Fractures, 29 (5): 49-55, 2009.

4- ZWICK E.B., Š VEHL1'K M. and STEINWENDER G.: Genu recurvatum in cerebral palsy part B: Hamtring are abnormally long in children with cerebral palsy showing knee recurvatum. J. Pediatr. Orthop. B., 19: 373-378, 2010.

5- SHUMWAY-COOK A. and WOOLLACOTT M.H.: Motor control: translating research into clinical practice. 3 rd ed. Philadelphia: Lippincott Williams \& Wilkins, 2007.

6- IMMS C. and GIBSON N.: An Overview of EvidenceBased Occupational and Physiotherapy for Children with Cerebral Palsy. In Cerebral Palsy (pp. 165-192). Springer, Cham., 2018.

7- RATEY J. and LOEHR J.: The positive impact of physical activity on cognition during adulthood: A review of underlying mechanisms, evidence and recommendations. Reviews in the Neurosciences, 22 (2): 171-185, 2011.

8- PEGGY PLETCHER: M.S., R.D., L.D., CDE on December 19, 2016.

9- LEHMAN G.J., HODA W. and OLIVER S.: Trunk muscle activity during bridging exercises on and off a Swiss ball Chiropractic and Osteopathy, 13: 14, 2005.

10- EL SHEMY S.A.: Trunk endurance and gait changes after core stability training in children with hemiplegic cerebral palsy: A randomized controlled trial. Journal of back and musculoskeletal rehabilitation, 31 (6): 1159-1167, 2018.

11- ESCAMILLA R.F., LEWIS C., BELL D., BRAMBLET G., DAFFRON J., LAMBERT S. and ANDREWS J.R.: Core muscle activation during Swiss ball and traditional abdominal exercises. journal of orthopaedic \& sports physical therapy, 40 (5): 265-276, 2010.

12- KATSAVELIS D. and THRELKELD A.J.: Quantifying thigh muscle co-activation during isometric knee extension contractions: Within-and between-session reliability. Journal of Electromyography and Kinesiology, 24 (4): 502-507, 2014.

13- Van VULPEN L., De GROOT S., RAMECKERS E., BECHER J. and DALLMEIJER A.: Improved walking capacity and muscle strength after functional powertraining in young children with cerebral palsy. Neurorehabilitation and neural repair, 31 (9): 827-841, 2017. 
14- SHAMSODDINI A., AMIRSALARI S., HOLLISAZ M., RAHIMNIA A. and KHATIBI-AGHDA A.: Management of spasticity in children with cerebral palsy. Iranian Journal of Pediatrics, 24 (4): 345, 2014.

15- LEVITT S. and ADDISON A.: Treatment of cerebral palsy and motor delay. Wiley-Blackwell, 3 (13): 10541059,2018

16- RETHLEFSEN S., BLUMSTEIN G., KAY R., DOREY F. and WREN T.: Prevalence of specific gait abnormalities in children with cerebral palsy revisited: Influence of age, prior surgery, and Gross Motor Function Classification System level. Developmental Medicine \& Child Neurology, 59 (1): 79-88, 2017.

17- KURZ M.J., WILSON T.W. and ARPIN D.J.: Stride-time variability and) sensorimotor cortical activation during walking. NeuroImage 1602-1607 (2 https://doi.org/ 10.1016/j. neuroimage.2011.08.084, 2012.

18-ABDEL-AZIEM A. and EL-BASATINY H.: Effectiveness of backward walking training on walking ability in children with hemiparetic cerebral palsy: A randomized controlled trial. Clinical rehabilitation, 31 (6): 790-797, 2017.

19- KIM S., RYU Y., JE H., JEONG J. and KIM H.: Backward walking treadmill therapy can improve walking ability in children with spastic cerebral palsy: A pilot study. International Journal of Rehabilitation Research, 36 (3): 246-252, 2013.

20- OLAMA K.A.: Endurance exercises versus treadmill training in improving muscle strength and functional activities in hemiparetic cerebral palsy. Egyptian Journal of Medical Human Genetics, 12 (2): 193-199, 2011.

21- GRECCO L.A.C., ZANON N., SAMPAIO L.M.M. and OLIVEIRA S.: Acomparison of treadmill training and overground walking in ambulant children with cerebral palsy: Randomized controlled clinical trial. Clin. Rehabil., 27 (8): 686-96, 2013.

22- KURZ M.J., CORR B., STUBERG W., VOLKMAN K.G. and SMITH N.: Evaluation of lower body positive pressure supported treadmill training forchildren with cerebral palsy. Pediatr. Phys. Ther., 23 (3): 232-9, 2011.

23- DAMIANO D.L. and DeJONG S.L.: A systematic review of the effectiveness of treadmill training and body weight support in pediatric rehabilitation. J. Neurol. Phys. Ther., 33 (1): 27-4491 (9): 747-60, 2009.

24- MASUMOTO K., SOUCY M.T., BAILEY J.P. and MERCER J.A.: Muscle activity during backward and forward running with body weight support. Hum. Mov. Sci., 55: 276-86, 2017

25- DODD K.J., TAYLOR N.F. and DAMIANO D.L.: A systematic review of the effectiveness of strength-training programs for people with cerebral palsy. Arch. Phys. Med. Rehabil., 83: 1157-64, 2002.

26- WILLOUGHBY K.L., DODD K.J., SHIELDS N. and FOLEY S.: Efficacy of partial body weight-supported treadmill training compared with over ground walking practice for children with cerebral palsy: A randomized controlled trial. Arch. Phys. Med. Rehabil., 91 (3): 333$9,2010$.

\section{تأثير تلدريب المشى بالخلف على المشاية الكهريائية على الانضار الخلفى للركبة فى حالات الشلال الدماغى في الأطفال}

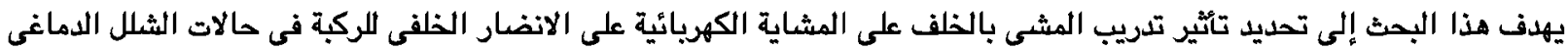

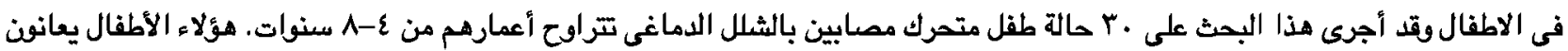

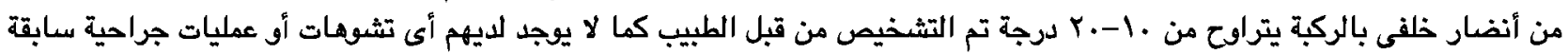

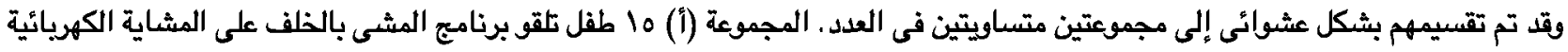

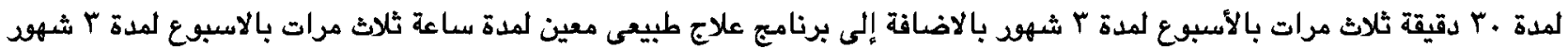

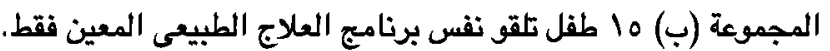

تم تجميع الأطفال فى العيادة الخارجية بمستشفى الشهداء المر كزى وتم قياس زاويا الركبة من خلال أشعة أكس وتطبيق كينوفيا للتحليل

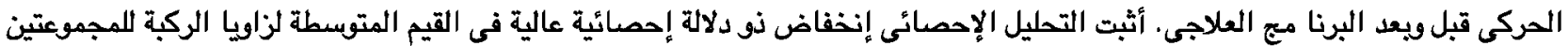

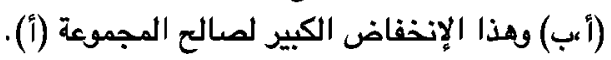

